\title{
WEAR CHARACTERISTICS AND VIBRATION ANALYSIS OF SHELL POWDER FILLED GLASS FIBER REINFORCED EPOXY COMPOSITE LAMINATES
}

\author{
Jyothish J Nair $^{1}$, Aji Augustine $^{2}$, Mahesh B Davanageri ${ }^{3}$ \\ ${ }^{1}$ Student, M Tech, Mechanical Machine Design, SCEM, Adyar, Mangalore, Karnataka, India \\ ${ }^{2}$ Student, M Tech, Mechanical Machine Design, SCEM, Adyar, Mangalore, Karnataka, India \\ ${ }^{3}$ Associate Professor \& Head, Department of Mechanical Engineering, SCEM, Adyar, Mangalore, Karnataka, India
}

\begin{abstract}
Research of composites with natural fillers is very useful in many engineering applications. The present study mainly deals with the fabrication of Glass/Epoxy Composites of 60-40\% composition with Sea shell powder as filler material. The composite plates are manufactured. The percentage of sea shell powder was varied by 5\%, 10\% and 15\% by volume. The dry sliding wear test was performed on a pin on disc arrangement. The wear tests were performed conventionally. The weight loss increased with more load, sliding velocity and distance. Scanning electron microscope was used to analyse the wear surface of composites. Modal Analysis is carried out using Fast Fourier Transform analyzer, accelerometer and impact hammer to determine the vibrational characteristics of the Glass/Epoxy composite. The analytical results are obtained from NX Nastran. The experimental and Analytical results are compared and they were in good agreement with each other. Glass/Epoxy with 5\% sea shell powder filler showed good vibrational characteristics.
\end{abstract}

Keywords: Composites, Shell Powder, Wear Test, and Vibration Analysis Etc...

\section{INTRODUCTION}

Composite material is a unique material which is originated by two or more materials combined together. Composite material has superior properties than the individual materials. A composite material consists of a matrix, reinforcement and interphase which are combined together in microscopic or macroscopic level. Some of the benefits of the composite materials are wear confrontation, high design flexibility, rigidity, and lower maintenance. Glass fiber based composite materials are widely used in automotive industries, aviation industries, electrical industries, chemical industries and sporting goods industries

Here we using epoxy polymer as the matrix material and glass fiber as reinforcement. The filler material is shell powder in different composition like 5\%, 10\% and 15\%.In today's scenario polymer composites play an important role in manufacturing and design fields. Engineers always keep on searching for the best material which will be cost effective that will suit certain design and product requirement. One of the main factors which make plastics attractive for engineering applications is the possibility of property modification through fibre reinforcement. Also, since the environmental awareness is growing significantly, one of the major factors to be considered in recent development of high performance materials is ecologically friendliness, that is materials with minimum effect on environment and this can be achieved by using renewable, recyclable, and biodegradable resources. Consequently in recent years, researchers have been studying on these types of materials as potential fillers in a polymer composite system. Although many investigations have been carried out on composites, ranging from metal matrix composites, ceramic matrix composites and polymer matrix composites in developed countries, but only few work has been done on polymeric composites reinforced with natural fibres or fillers. In the development of polyester/eggshell particulate composites, observations showed that the density and hardness values of the composite increased directly with increasing eggshell addition [9]. One of the major works on polyester composite with sea shell as filler material. The filler material used was of size 250 microns. They investigated the properties for various compositions of sea shell powder and concluded that the composite with $10 \%$ of filler material yielded better results [8]. Seashell is purely natural and readily available. Experimental studies on vibration of hybrid polymer composites concluded that hybrid composites are more capable than glass reinforced composites[2]. wear performance of composites is studied in many regions of the world. SiC filled composites subjected to three body wear mechanism, then wear rate was found to be more with higher load, velocity and abrading distance. The silicon carbide filler improved the wear properties of the composites [4]. SEM analysis is introduced to study the worn surface and bonding of fiber and matrix[3].The fabrication of glass epoxy composite with sea shell filler is carried out here. Major testing considerations are vibrational behavior and wear performance of the composite. Pin on disc tribometers are used for the wear test. the observations and results regarding tests are explained in this study. 


\section{MATERIALS AND FABRICATION}

Composites are fabricated using either by hand layup method or by spray up method. Hand layup method is very simple and widely used to make composites. Epoxy is used as matrix and glass fibers are used as reinforcement for the fabrication of the composite.

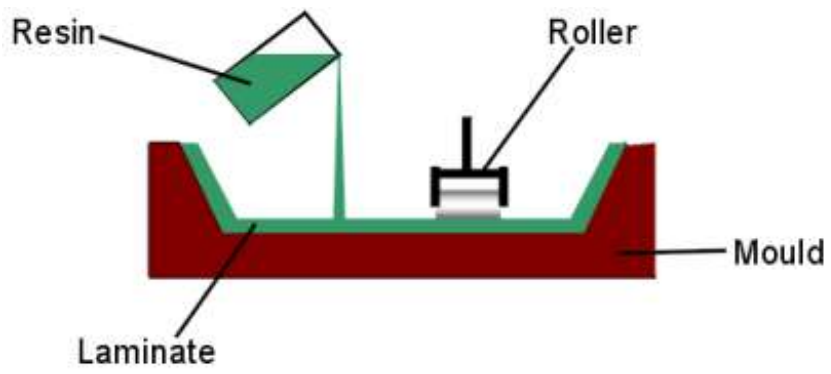

Fig -1: Hand lay-up process

Hand lay-up routine is used to fabricate the glass epoxy composite with shell powder filler. Glass fiber and epoxy are supplied by yuje enterprises Bangalore. The representation of the hand lay-up technique is as shown in fig. In plywood stand a thick cellophane sheet is kept and Vaseline and coconut oil spread over the surface of the sheet. Over the cellophane sheet, one layer of glass fiber of $300 \times 300 \times 30 \mathrm{~mm}$ was placed. It was made sure that there was no air present in between cellophane sheet and fiber layer. Epoxy is mixed with $10 \%$ of hardener and shell powder as per calculations poured into a container. It's properly mixed for few minutes and ensures that the proper curing takes place. The mixture is then smeared over the glass fiber and another woven glass fiber layer kept over the epoxy resins and air gaps removed. The same procedure followed for the required number of layers. A cellophane sheet smeared with Vaseline and coconut oil placed over the last layer of glass fiber. For compression purpose steel plate is kept above the plate. The composite is then cured for a day. Then it's kept in sunlight for further curing. Material is cut as per the specimen dimensions for the testing purpose. Materials used for the fabrication are

1. E Glass as reinforcement

2. Epoxy resin (LAPOX 12)

3. Hardener (K6)

4. Shell powder

5. Vaseline and coconut oil (releasing agents)

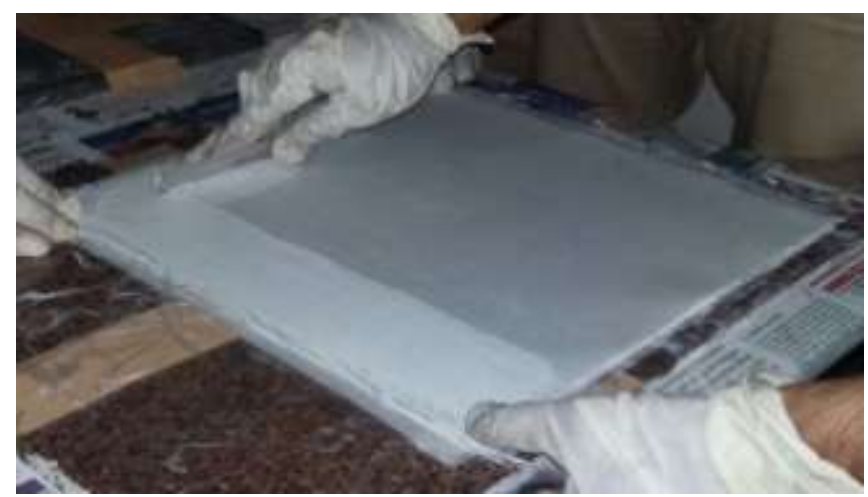

Fig -2: Composite material preparation

\subsection{Filler Material}

Sea shell powder is used as filler material. Shell exists solid in nature which is smooth and white color in powdered form. Shell is a part of animal body. It's the exoskeleton of an animal. It finds industrial application like construction, cement, food processing.

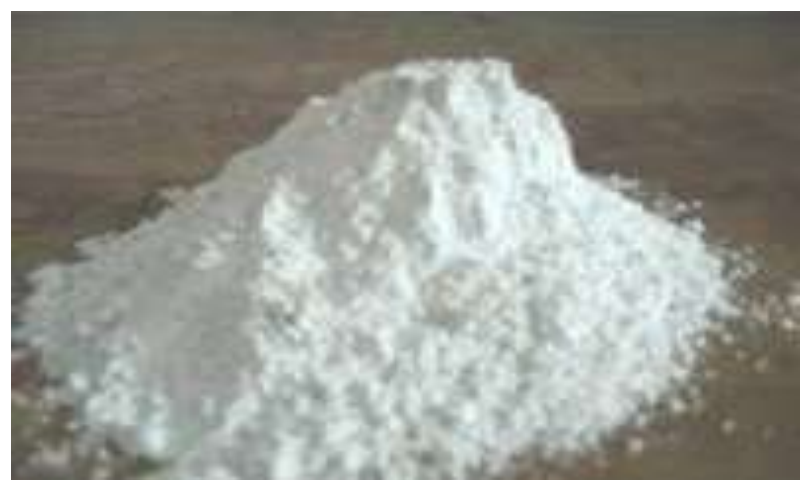

Fig -3: Shell powder

\section{EXPERIMENTATION}

The main objective of the present study is to analyze the vibrational behavior and wear characteristics of the composite test specimens.

\subsection{Vibration of Composite Plate}

Damping test is conducted in the SOLVE lab at NITK surathkal. A FFT analyzer setup includes a hammer, accelerometer, FFT analyzer and PC with pulse lab view software. Pulse lab view version 3.0 software is used. The pulse lab view software key is associated with the harbor of PC. Utilizing the hammer the fixed end of the model is excited and free part of the FFT set up is affiliated with accelerometer (YMC121A100 IEPE).

For cantilever limiting condition one end is fixed and other end is free. The total length of the specimen as per cantilever boundary condition is $200 \mathrm{~mm}$ and $20 \mathrm{~mm}$ length of the composite is fixed. The accelerometer is attached to the YMC121A100 IEPE sort and temperature ranges between -40 to $121^{\circ} \mathrm{C}$. The output signal analyzer is displayed on the screen with the help of pulse software. Frequency Response Functions (FFR) is readily available in different form. The specimen dimensions for the FFT is $200 * 20 * 3 \mathrm{~mm}$.

The cantilever beam is energized by a model hammer using very small force. The accelerometer sense the vibration induced by hammer. FFT analyzer analyse the signals from accelerometer and the output signals are shown in the pulse software. The pulse software output includes frequency v/s amplitude, frequency v/s phase, and time v/s amplitude. For different composition of specimens different mode value of frequency is obtained. 


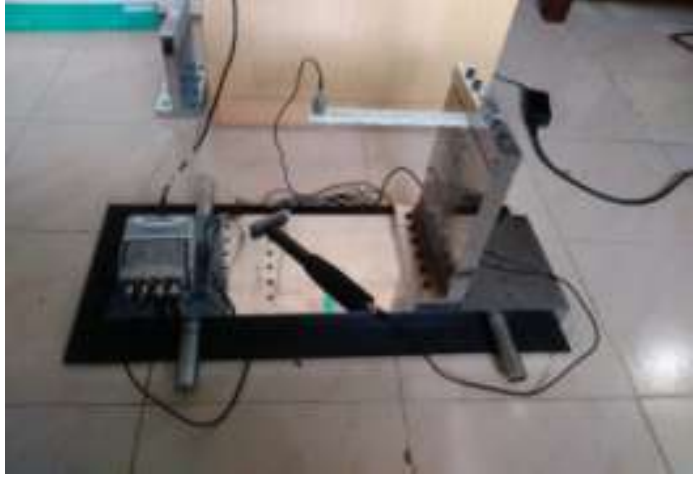

Fig -4: Damping Test Setup

\subsection{Pin on Disc Wear Test}

Wear test is used for predict the wear performance and study the wear mechanism. Different wear testing methods are available but most common and our method is using pin on disc wear testing apparatus. It consists of a stationery pin placed on a rotating disc. The specimen is taken as pin material and loading conditions are applied on pin. Speed and travelling distance are also variables in pin on disc experiment. DUCOME tribometers are used for the experimental work. The disc plate is made up of EN31 case hardened steel about $60 \mathrm{HRC}$. Wear depth (mm), coefficient of friction, frictional force $(\mathrm{N})$, temperature during the experiment are the major parameters measured during the experiment. The wear volume is calculated by measuring the weight of the specimen using digital weight balance before and after the wear test.

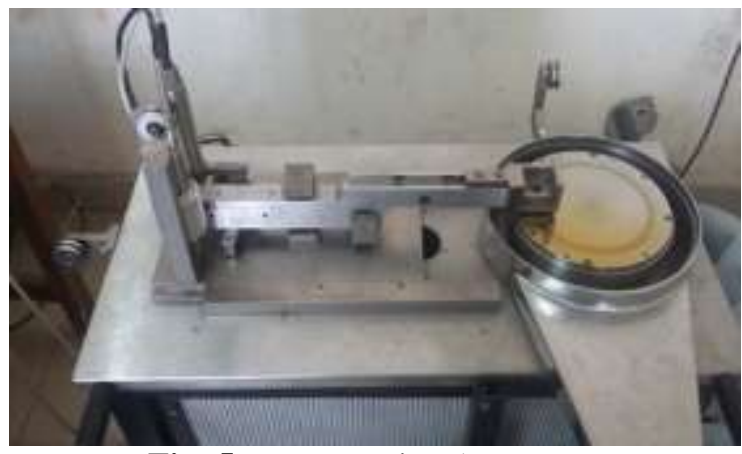

Fig -5: Wear Testing Apparatus

\section{RESULTS AND DISCUSSIONS}

\subsection{Damping Test Results}

The fundamental frequencies of the specimens are obtained from FFT test. Using half-power bandwidth method, the dampingratio and logarithmic decrement are calculated and are represented in the table.

From the table, it is clear that maximum damping value is obtained for $10 \%$ filler content composite specimen. Hence this ratio exhibits better damping property. Composites with $5 \%$ and $15 \%$ composition of fillers exhibiting lower damping performance than $10 \%$ filler composites. The frequency response curves of the specimens are shown in the figure below.
Table -1: Values of Frequency for Mode 1, Logarithmic Decrement and Damping Ratio

\begin{tabular}{|l|l|l|l|}
\hline Filler \% & $\begin{array}{l}\text { Frequency for } \\
\text { Mode 1 }(\mathrm{Hz})\end{array}$ & $\begin{array}{l}\text { Logarithmic } \\
\text { Decrement } \delta\end{array}$ & $\begin{array}{l}\text { Damping } \\
\text { Ratio } \varepsilon\end{array}$ \\
\hline $5 \%$ & 37.376 & 0.010 & 0.065 \\
\hline $10 \%$ & 36.864 & 0.014 & 0.087 \\
\hline $15 \%$ & 36.352 & 0.011 & 0.067 \\
\hline
\end{tabular}

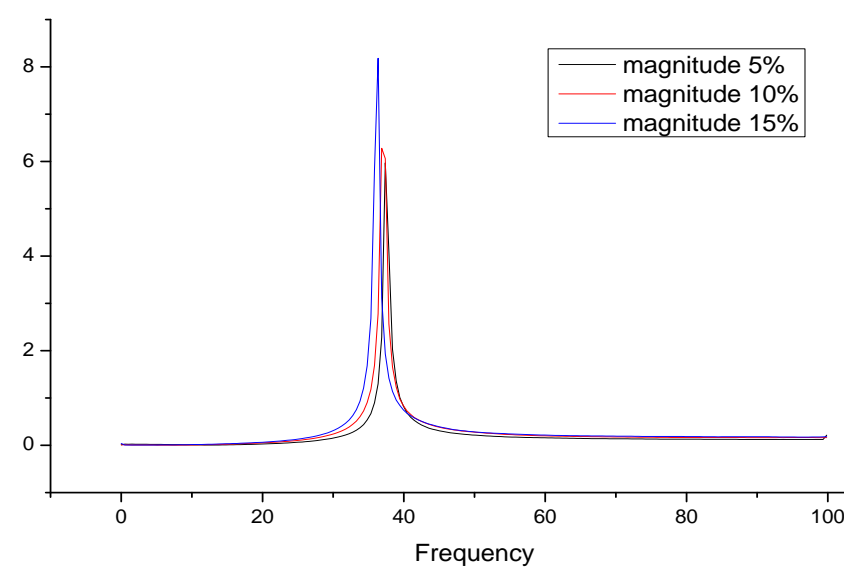

Fig -6: Combined Vibration Test Results

\subsection{FEM Modal Analysis}

The modal analysis is done on NX NASTRAN software to compare the fundamental natural frequencies of a composite samples analytically with the experimental values obtained from the impact hammer testing. This analysis is performed to determine the natural characteristics such as fundamental frequency and mode shapes of the composite specimen. Natural frequency is found for first mode shape of each of the composite specimen and the corresponding modal behavior is shown in the figure below.

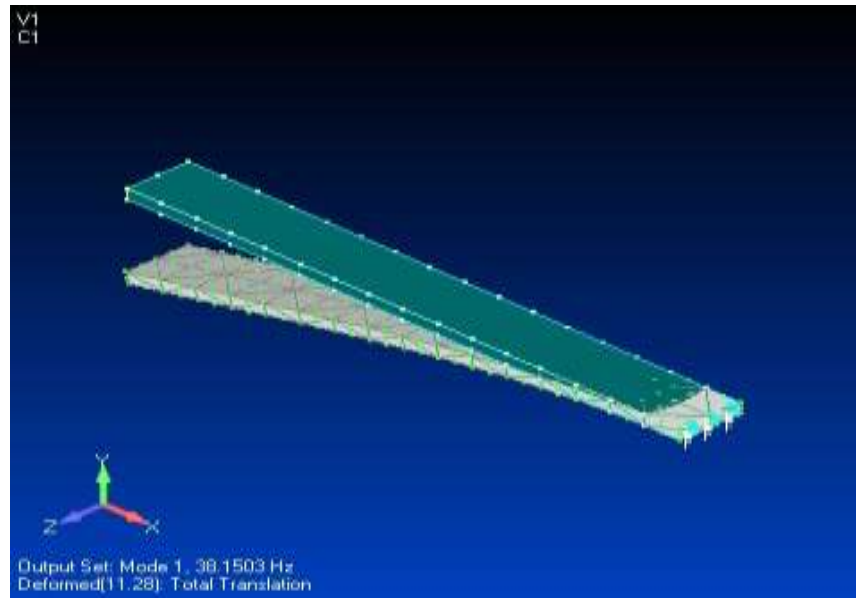

Fig -7: Mode 1 analysis for 5\% Filler material 


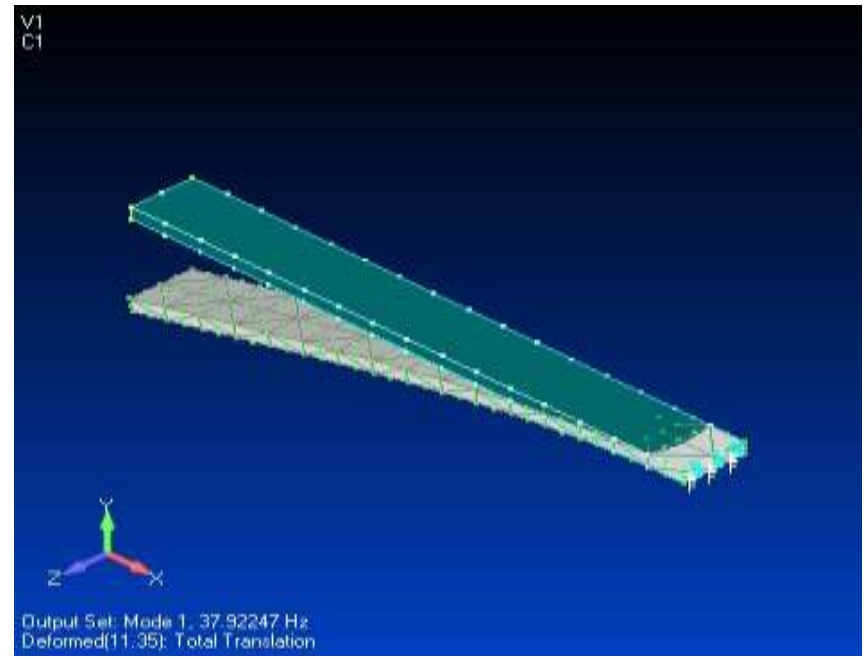

Fig -8: Mode 1 analysis for $10 \%$ Filler material

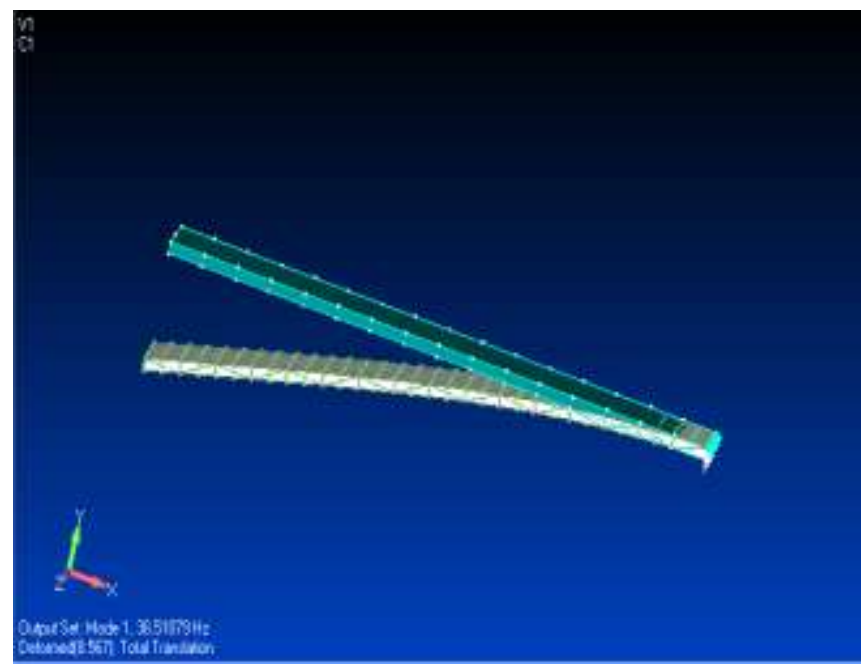

Fig -9: Mode 1 analysis for 15\% Filler material

\subsection{Comparison of Frequency Value}

The values of natural frequencies for first mode obtained experimentally are compared with that of analytical values for all filler contents.

Table -2: Comparison of Frequency values of Glass/Epoxy Composite Plates of different Compositions

\begin{tabular}{|l|l|l|}
\hline Filler \% & $\begin{array}{l}\text { Experimental } \\
(\mathrm{Hz})\end{array}$ & $\begin{array}{l}\text { Analytical } \\
(\mathrm{Hz})\end{array}$ \\
\hline $5 \%$ & 37.376 & 38.15 \\
\hline $10 \%$ & 36.864 & 37.92 \\
\hline $15 \%$ & 36.352 & 36.51 \\
\hline
\end{tabular}

It is found that the experimental values are very near to the analytical values as determined using NX Nastran. So these values can be directly considered to find the damping behavior of the composite specimens.

\subsection{Wear Test Results}

Dry sliding wear tests were performed on the specimens fabricated using hand layup method. Conventional method of experimentation was followed. Wear tests for different loads, sliding distance and sliding velocity were conducted. Two parameters kept constant and one parameter varied while testing. The loss of weight for each condition was recorded. Each parameter varied in five steps. The effect of sliding distance, sliding velocity and load applied are discussed.

\subsubsection{Influence of Load Applied on Wear}

The wear tests were conducted for various loads keeping the sliding distance and speed constant. The sliding speed was kept constant at $400 \mathrm{rpm}$. The sliding distance was kept constant at 400 . The weight loss of each tested specimens were recorded.

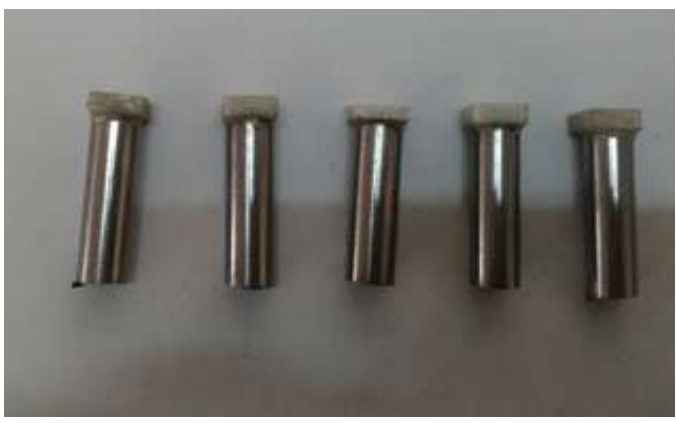

Fig -10: Wear Test Specimens

Table -3: Weight lossvarying load at constant sliding speed and distance

\begin{tabular}{|l|l|l|l|l|l|}
\hline Load & Sliding & \multirow{2}{*}{$\begin{array}{l}\text { Sliding } \\
\text { velocity }\end{array}$} & \multirow{2}{*}{$\begin{array}{l}\text { distance } \\
(\mathrm{r})\end{array}$} & \multicolumn{3}{|l|}{ Weight loss $(\mathrm{g})$} \\
\cline { 3 - 6 } & & $5 \%$ & $10 \%$ & $15 \%$ \\
\hline 10 & 400 & 400 & 0.00026 & 0.00022 & 0.0002 \\
\hline 15 & 400 & 400 & 0.0004 & 0.00034 & 0.0003 \\
\hline 20 & 400 & 400 & 0.00053 & 0.0005 & 0.00045 \\
\hline 25 & 400 & 400 & 0.00064 & 0.0006 & 0.00054 \\
\hline 30 & 400 & 400 & 0.0007 & 0.00064 & 0.00057 \\
\hline
\end{tabular}

The load applied increases the weight loss also increases. The weight loss decreases with increase in weight percentage of the filler material. It can be seen that $5 \%$ shell powder filled composite experiences more weight loss in comparison with the other composites.

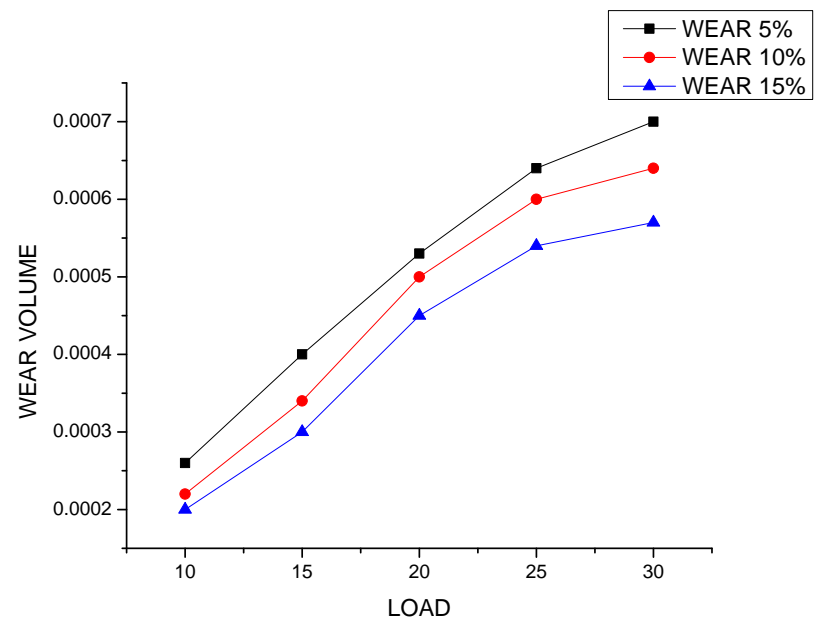

Fig -11: Weight loss of composites for load varying from $10 \mathrm{~N}$ to $30 \mathrm{~N}$ 


\subsubsection{Influence of Sliding Speed on Wear}

The dry sliding wear test performed for different sliding velocities. The material weight loss of the tested specimens were calculated, the wear tests were conducted keeping load and sliding distance constant. Load is $20 \mathrm{~N}$ and sliding distance 400m.

Table -4: Weight lossfor varying velocity at constant load and distance

\begin{tabular}{|l|l|l|l|l|l|}
\hline \multirow{2}{*}{$\begin{array}{l}\text { Load } \\
(\mathrm{N})\end{array}$} & \multirow{2}{*}{$\begin{array}{l}\text { Sliding } \\
\text { velocity } \\
(\mathrm{rpm})\end{array}$} & \multirow{2}{*}{$\begin{array}{l}\text { Sliding } \\
\text { distance }\end{array}$} & \multicolumn{4}{|l|}{ Weight loss $(\mathrm{g})$} & $5 \%$ & $10 \%$ & $15 \%$ \\
\cline { 4 - 6 } & & 400 & 0.0003 & 0.00026 & 0.00024 \\
\hline 20 & 100 & 400 & 0.0004 & 0.00035 & 0.00032 \\
\hline 20 & 200 & 400 & .00054 & 0.00045 & 0.00046 \\
\hline 20 & 400 & 400 & .00064 & 0.00054 & 0.00052 \\
\hline 20 & 500 & 400 & 0.00074 & 0.00062 & 0.00055 \\
\hline
\end{tabular}

Weight loss also increases with the increase in sliding velocity. Reduction of weight loss of composites with the increase in weight percentage of the filler material can be observed. Composite with $5 \%$ of shell powder filler experience more weight loss. $15 \%$ shell powder filled composite have less weight loss.

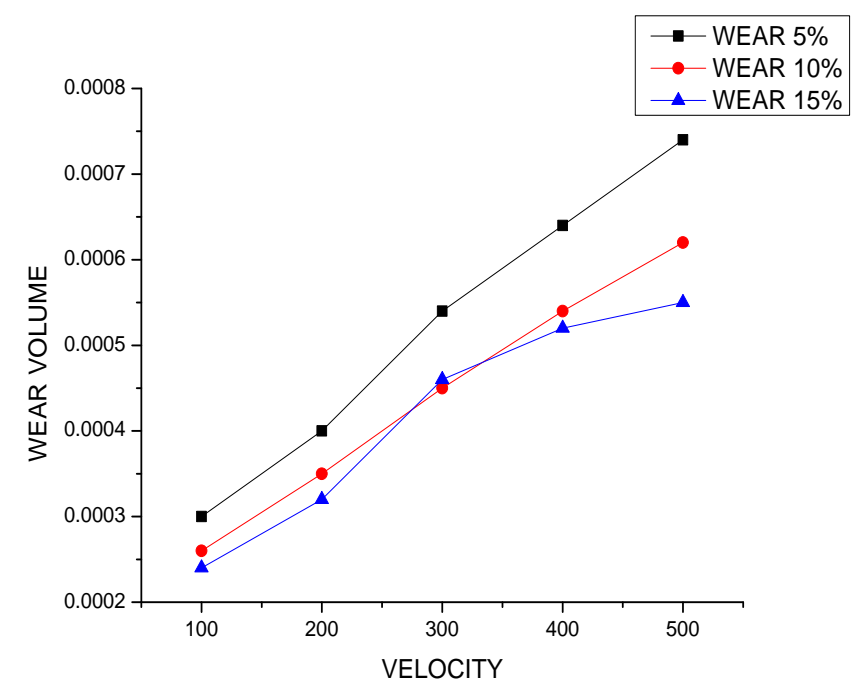

Fig -12: Weight loss for sliding velocity varying from 100 to $500 \mathrm{rpm}$

\subsubsection{Influence of Sliding Distance on Wear}

Dry sliding wear tests were carried out for varying sliding distance keeping the sliding velocity and the applied load constant. For every test specimen weight loss was measured and recorded. The specific wear rate is also calculated. The constant sliding velocity 400rpm and applied load $20 \mathrm{~N}$ was maintained.
Table -5: Weight loss for varying distance at constant velocity and load applied

\begin{tabular}{|l|l|l|l|l|l|}
\hline \multirow{2}{*}{$\begin{array}{l}\text { Load } \\
(\mathrm{N})\end{array}$} & \multirow{2}{*}{$\begin{array}{l}\text { Sliding } \\
\text { velocity }\end{array}$} & \multirow{2}{*}{$\begin{array}{l}\text { Sliding } \\
\text { distance }\end{array}$} & \multicolumn{3}{l}{ Weight loss $(\mathrm{g})$} \\
\cline { 4 - 6 } & $(\mathrm{rpm})$ & & $5 \%$ & $10 \%$ & $15 \%$ \\
\hline 1 & 20 & 100 & 0.0002 & 0.00017 & 0.00014 \\
\hline 2 & 20 & 200 & 0.00031 & 0.00026 & 0.00023 \\
\hline 3 & 20 & 300 & .00047 & 0.00042 & 0.00036 \\
\hline 4 & 20 & 400 & .00062 & 0.00057 & 0.00052 \\
\hline 5 & 20 & 500 & 0.00079 & 0.0007 & 0.00063 \\
\hline
\end{tabular}

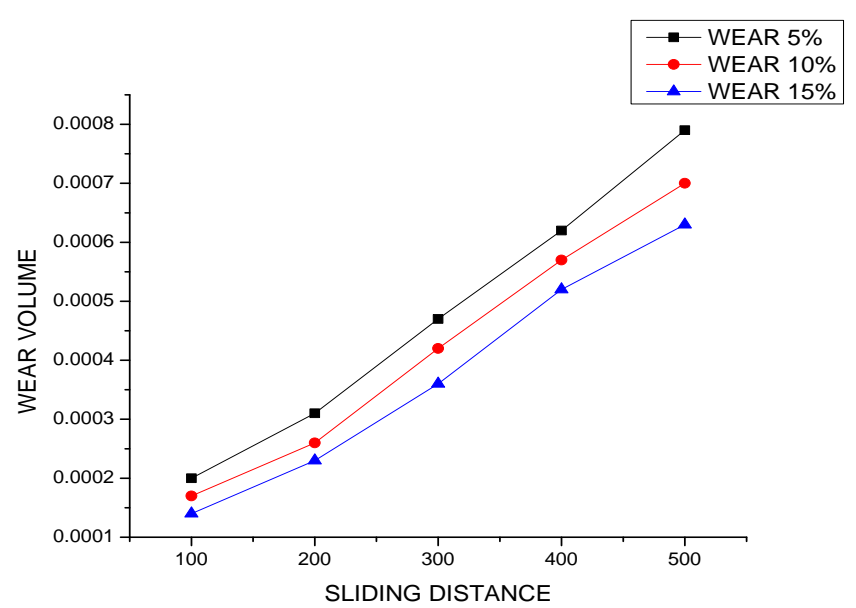

Fig -13: Weight loss for sliding distance varying from $100 \mathrm{~m}$ to $500 \mathrm{~m}$

It can be seen that the weight loss of the composites increases as the sliding distance increases. As the filler content in the test specimen escalate the weight loss decreases. Composite material having $15 \%$ sea shell powder as filler content shows lower weight loss compared with the other composites at higher sliding distances.

\subsection{SEM Analysis}

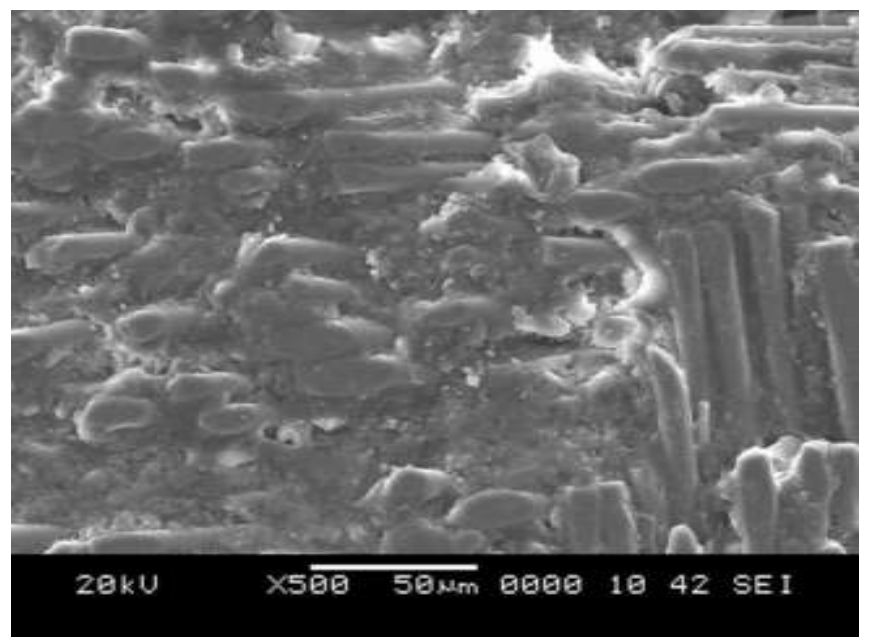

Fig -14: SEM micrograph of glass-epoxy composite with $5 \%$ at $20 \mathrm{~N}$ and $400 \mathrm{~m}$ with a sliding velocity of $400 \mathrm{rpm}$

Figure-14shows SEM micrograph of filled glass/epoxy composite with $5 \%$ of sea shell powder. The wear rate is more in this composite. The breakage of fibers is very 
prominent in and imprints caused by the removal of fibers are visible in the SEM. The contact between the disc and the composite causes ploughing action thereby debris are formed. Debris caused an abrasive wear effect and wear of material increased.

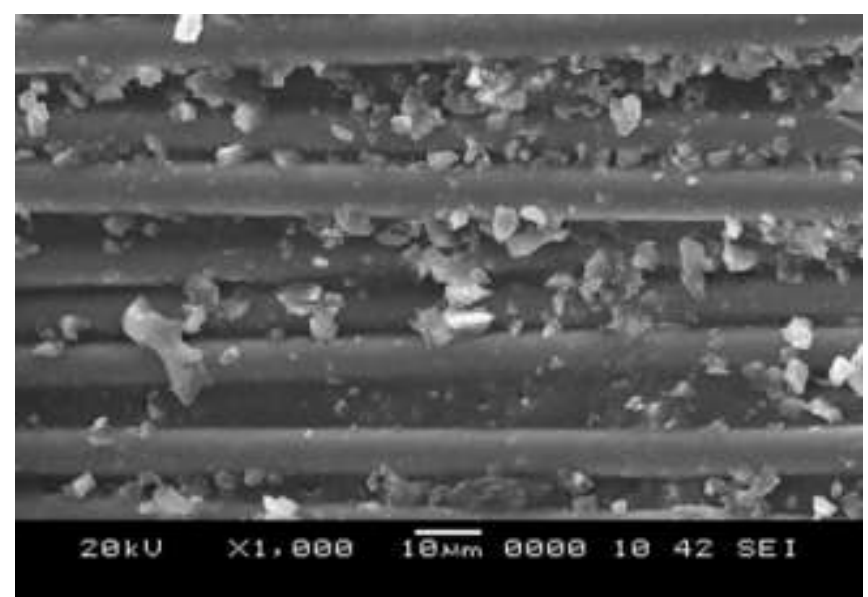

Fig -15: SEM micrograph of glass-epoxy composite with $10 \%$ at $20 \mathrm{~N}$ and $400 \mathrm{~m}$ with a sliding velocity of $400 \mathrm{rpm}$

Figure-15shows SEM image of filled glass/epoxy composite with $10 \%$ sea shell powder. From the micrograph it's visible that a part of particulate fillers stand out of the matrix. These protrusions helps carry a part of load applied and thereby avoiding a stronger adhesion between the steel disc and the matrix in the composite. Ploughing action is reduced. Comparatively lower damage to the matrix and epoxy seen in the composite with $10 \%$ filler material.

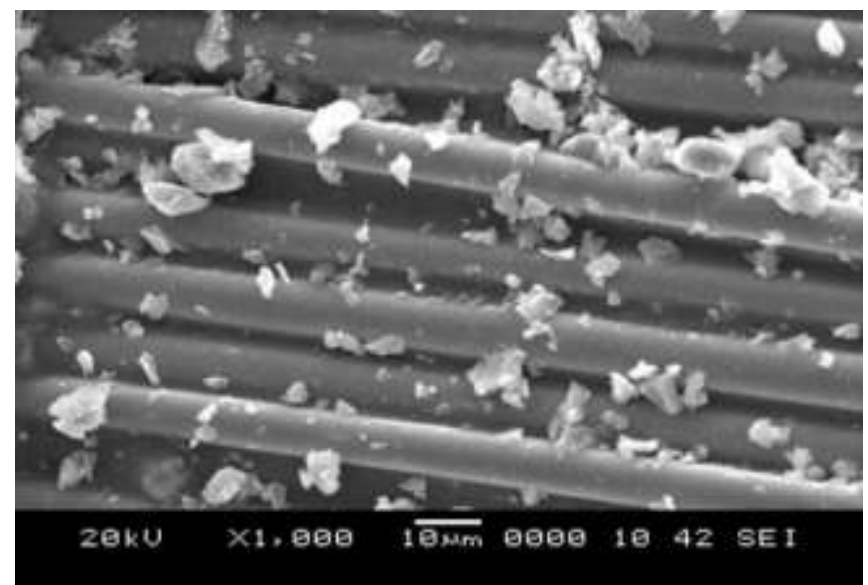

Fig -16: SEM micrograph of glass-epoxy composite with $15 \%$ at $20 \mathrm{~N}$ and $400 \mathrm{~m}$ with a sliding velocity of $400 \mathrm{rpm}$

Figure-16shows the SEM image of glass/epoxy composite with $15 \%$ sea shell powder filler. The worn surface visible in the image has a smoother surface. Smoother surface of the composites also a result of lower specific wear rate. A gradual wear process of matrix maintaining the fibers can be observed. A good bonding strength and reduction of voids in filled epoxy reinforced with glass fibers can help improve the resistance to wear.

\section{CONCLUSION}

The tests conducted on the Composite showed that the Filler material affected the properties of Composite Material. The tests for Vibration gave better results for $5 \%$ which gave lower logarithmic decrement than $15 \%$ and $10 \%$ compositions. As the logarithmic decrement was found to be lower it means the material can withstand vibrations better than that of $15 \%$ and $10 \%$ composition materials.

Wear tests for the composites gave better result for $15 \%$ filler material. The worn surface morphology shows that the composites undergo micro cracking and ploughing actions during wear.

\section{REFERENCES}

[1]. Itishree Mishra \&Shishir Kumar Sahu "An Experimental Approach to Free Vibration Response of Woven Fiber Composite Plates under Free-Free Boundary Condition", International Journal of Advanced Technology in Civil Engineering, ISSN: 2231 -5721, Volume-1, Issue-2, 2012.

[2]. Dr.P.S.Senthil Kumar, Karthik.K And Raja.T "Vibration Damping Characteristics of Hybrid Polymer Matrix Composite", International Journal of Mechanical \& Mechatronics Engineering IJMME-IJENS Vol:15 No:01,2015

[3]. P. Ganesa and S. Thirumavalavan "Free Vibration Behaviour of Glass Fiber Reinforced Polymer Composite", Middle-East Journal of Scientific Research 20 (6): 734-737, 2014.

[4]. Xu Lei, Wang Rui, Liu Yon and Li Jin "The Effect of Woven Structures on the Vibration Characteristics of Glass Fabric/Epoxy Composite Plates", Defence Science Journal, Vol.61, No.5,pp. 499-504,2011

[5]. SudeepDeshpande and T. Rangaswamy "Sliding Wear Characteristics of Bone Powder Filled Hybrid Fiber Reinforced Epoxy Composites", IOSR Journal of Mechanical and Civil Engineering (IOSR-JMCE), ISSN: 2320-334X, Volume 13, (Jan. - Feb. 2016), PP 68-78

[6]. N. Mohan, C.R Mahesha, R. Raja, "Tribo-mechanical behaviour of $\mathrm{SiC}$ filled glass-epoxy composites at elevated temperatures", International journel of engineering, science and technology, 2014, Vol.6, No.5, pp.44-56.

[7]. S. Basavarajappa, S. Ellangovan, "Dry sliding wear characteristics of glass-epoxy composite filled with silicon carbide and graphite particles", Elsevier B. V., 2012, pp. 491-496.

[8]. AbiodunAdemolaOdusanya, BabatundeBolasodun, ChiomaIfeyinwaMadueke "Property Evaluation of Sea shell Filler Reinforced Unsaturated Polyester Composite", International Journal of Scientific \& Engineering Research, Volume 5, Issue 11, November-2014.

[9]. S.B.Hassan ,V.S.Aigbodion , S.N.Patrick "Development of polyester/eggshell particulate composites." Tribology in industry vol 34,no 4 (2012) 217-225. 


\section{BIOGRAPHIES}

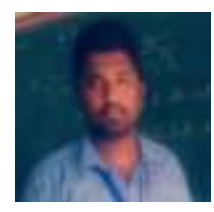

Jyothish J Nair completed M.Tech (Machine Design) from Sahyadri College of Engineering and Management Mangalore. He received BE degree from VCET Puttur.

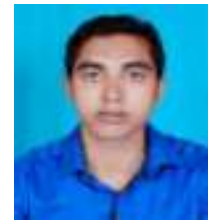

Aji Augustine completed M.Tech from Sahyadri College of Engineering and Management Mangalore. He received B.Tech degree from Sree chitratirunal college of engineering Trivandrum.

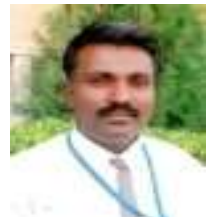

Mahesh B Davanageri is working in Sahyadri College of Engineering and Management as Associate Professor \& Headin the department of Mechanical engineering. He received M.Tech in Design Engineering degree from K.L.E College of Engineering Belgaumand $\mathrm{BE}$ degree in Industrial Production from M.C. E. Hassan. He has published 5 International journals and he carried out paper presentation in 4 national and 1 international conference. 